\title{
Lower prevalence of asthma and atopy in Turkish children living in Germany
}

\author{
M. Kabesch, W. Schaal, T. Nicolai, E. von Mutius
}

\begin{abstract}
Lower prevalence of asthma and atopy in Turkish children living in Germany. M. Kabesch, W. Schaal, T. Nicolai, E. von Mutius. (C)ERS Journals Ltd 1999.

ABSTRACT: Ethnic origin has been reported to affect the prevalence of atopic diseases in several studies in different parts of the world. However, little is known about the prevalence of asthma and atopy in immigrants living in Europe. The objective of this study was to evaluate the prevalence of asthma and atopy in Turkish children living in Germany and to investigate the role of ethnic origin on the development of asthma and atopy in this population.

In a cross-sectional survey the prevalence of physician-diagnosed asthma, atopy, skin-prick tests and bronchial hyperresponsiveness (BHR) to cold dry air challenge was assessed in 7,445 school children aged 9-11 yrs, living in Munich, south Germany. Questionnaires were distributed to the parents for self-completion and children underwent skin prick tests and cold air hyperventilation challenge.

The Turkish children showed a significantly lower prevalence of asthma ( 5.3 versus $9.4 \%, p<0.05)$ than their German peers. Furthermore, atopy, as assessed by skin prick tests $(24.7$ versus $36.7 \%, p<0.001)$ and BHR (3.9 versus $7.7 \%, p<0.001)$, was less common in Turkish children. In multivariate regression models controlling for potential explanatory factors, Turkish origin still showed a significantly lower risk of developing asthma, atopic sensitization and BHR.

The prevalence of childhood asthma was therefore shown to be lower in Turkish children living in Germany than in Turkey. These findings suggest that the lower prevalence of asthma and allergy in Turkish children living in Germany might be attributable to a selection bias affecting the parents of these children, as healthy individuals may have decided to come to Germany for work.

Eur Respir J 1999; 13: 577-582.
\end{abstract}

University Children's Hospital, Munich, Germany.

Correspondence: M. Kabesch

Universi-tätskinderklinik

Lindwurmstr. 4

D-80337 München

Germany

Fax: 498951604452

Keywords: Asthma

atopy

childhood

ethnicity

prevalence

Turkish

Received: April 281998

Accepted after revision October 251998
The difference in the prevalence of asthma in various parts of the world cannot entirely be explained by differences in methodology. Studies in children rather suggest a high prevalence of asthma in the UK, Australia and New Zealand compared with moderate prevalence rates in most Western European countries [1, 2] and low prevalence rates in Eastern Europe [3-5] and developing countries [6]. Moreover, the prevalence of asthma varies not only between countries but also between centres within the same country [7]. Even within study centres there are differences in the prevalence rates of atopic diseases as has been demonstrated in the USA [8], New Zealand [9] and Australia [10].

Among other explanatory factors, ethnicity was found to be associated with different prevalence rates of asthma and atopy in childhood. The reasons for these differences are still obscure. Genetic, lifestyle or environmental factors may account for these variations [8, 10-13]. In Europe, immigration for political or economical reasons from all over the world to countries such as France, the UK, Germany and the Netherlands leads to significant changes in the population structure. However, very little is known about the impact of ethnicity on the development of asthma and atopic diseases in Europe.

The aim of this analysis was to evaluate the prevalence of asthma and atopic diseases in Turkish children living in Germany and to study the relevance of associated risk. The methods used in this study have been published previously [3]. Only methods pertaining to this analysis are given below.

\section{Subjects and methods}

\section{Subjects}

Between September 1989 and July 1990 fourth-grade pupils, mainly 9-11 yrs of age, at all primary schools in Munich, south Germany, were enrolled in a cross-sectional survey. Questionnaires were sent through the schools to 7,445 families for self-completion. Children underwent skin prick testing, pulmonary function testing and bronchial challenge to cold air. Informed written consent was obtained from parents separately for skin prick testing, lung function testing and cold air challenge. All study methods were approved by the Ethics Committee of the Bavarian Medical Association.

\section{Questionnaire}

A self-administered questionnaire according to international standards was distributed to the parents of all children. Questions concerning ethnic origin, sociodemographic characteristics, symptoms and diagnosis of respiratory and allergic disorders and their possible risk 
factors were included. The questionnaire was translated into Turkish and given to parents of Turkish children.

Ethnic origin was assessed by asking the question "What is the child's nationality?" In Germany, in contrast to many other countries, a child's nationality depends on the parental citizenship regardless of the child's place of birth. Children whose parents reported either asthma, recurrent spastic or recurrent asthmatic bronchitis were classified as having asthma, also referred to as "asthma ever" in the text and tables. Asthma with symptoms in the last 12 months was defined as current asthma. Children whose parents reported recurrent bronchitis without asthma were classified as having bronchitis. The occurrence of hay fever and atopic dermatitis was assessed by asking the questions: "Has a doctor ever diagnosed hay fever in your child?" and "Has your child ever had atopic dermatitis?" A child was considered wheezy if recurrent symptoms of wheeze were reported by the parents. Questions used to assess other symptoms were: "Has your child ever had attacks of shortness of breath?", "Does your child frequently cough at night without having a cold?" and "Does your child frequently cough after exercise or during foggy or cold weather?"

The family history of atopic diseases was assessed by the question: "Did you or a family member ever suffer from asthma, hay fever or atopic dermatitis?" Children with one or more nearest of kin (i.e. parents or siblings) with at least one of these allergic diseases were defined as having a positive family history of atopy. Further questions concerning possible risk factors for the development of asthma and atopic diseases were asked. These questions included: "How many siblings has your child?", "What is the mean number of cigarettes smoked daily in your household?", "Has your home been damaged by dampness?", "Which heating system is mainly used in your household?" and "Do you have pets in your home and if yes, which pets are these?" To evaluate the socioeconomic status of the families, parental education was assessed by asking about the highest degree earned by either the father or the mother.

\section{Skin prick test}

Sensitivity to six common aeroallergens (Dermatophagoides pteronyssinus, mixed grasses, birch and hazel pollen, cat and dog dander) was assessed by a multitest device (Stallerkit $\AA$; Stallergènes, Lyon, France). All allergen extracts were standardized in biological units. Results obtained using this device had been validated in a pilot study in Munich [14].

A child was considered sensitized if a weal reaction of $>3 \mathrm{~mm}$ was present to a specific allergen after subtraction of the negative control. A child was considered atopic if a positive weal reaction to at least one of the six allergens tested was present.

\section{Pulmonary function test and bronchial challenge}

Pulmonary function testing was performed with the pneumoscope II (Jäger, Würzburg, Germany). Forced flow-volume curves were repeated until three reproducible loops were obtained. Isocapnic hyperventilation of cold, dry air was applied as the bronchial provocation method.
To perform the cold air challenge a respiratory heatexchange system (Jäger) was used. The test consisted of 4 min of isocapnic $\left(5 \% \mathrm{CO}_{2}\right)$ hyperventilation (i.e. $(22 \times$ $\mathrm{FEV} 1) / \mathrm{min})$ of dry cold air $\left(-15^{\circ} \mathrm{C}\right.$, measured at the mouthpiece). A target balloon guided the ventilatory effort. It was constantly filled with air at a predetermined rate and had to be held in the constant filling state throughout the provocation test by the child's respiratory effort. Lung function tests were performed before and 2-4 min after the cold air hyperventilation challenge.

To compare baseline lung function between German and Turkish children, predicted values were calculated. A reference population of German and Turkish children without a diagnosis of asthma and without wheeze and shortness of breath ever was identified. Within this reference population, baseline lung function values, which had been transformed on a logarithmic scale, were regressed with weight and height as logarithmically transformed covariates for Turkish and German males and females separately.

To assess bronchial hyperresponsiveness (BHR), changes in forced expiratory volume in one second (FEV1; in \%) were calculated as: (FEV1 after inhalation -FEV1 before inhalation $) \times 100 / \mathrm{FEV} 1$ before inhalation $(\Delta \mathrm{FEV} 1)$. BHR was defined as a drop in FEV1 as large as or larger than the value of the 95 th percentile $(9 \%$ fall in FEV1) of the reference population (German children without asthma, hay fever or atopy), as reported in a previous work [15].

\section{Statistical analysis}

The Wilcoxon test was used to compare the distribution of age, height and weight in Turkish and German children. Prevalence rates were calculated and Chi-squared tests were used to assess differences between the two groups. A multivariate logistic regression analysis was computed to assess the independent effects of several potential determinants of asthma and atopic sensitization. The drop in FEV1 after cold air challenge was adjusted in a multivariate linear regression model for the following variables: height, nationality, family history of atopy, number of positive weal reactions, passive smoking and the FEV1/ forced vital capacity (FVC) ratio. The SAS software package version 6.12 (SAS Institute, Cary, NC, USA) was used for all calculations.

\section{Results}

Of the 7,445 families sent questionnaires 6,490 responded $(87 \%)$. Of the responders, 5,030 $(77.5 \%)$ were of German origin, $451(7 \%)$ were of Turkish origin and 1,009 $(15.5 \%)$ were of various other ethnic origins (435 Yugoslavian, 21 Greek and 456 from nationalities not further specified in the questionnaire). As Yugoslavian nationality comprises children from different ethnic origins (Bosnia, Serbia, Croatia and Slovenia), the analysis of these data is not presented. However, the results followed the same trends as those described for Turkish children (data not shown).

Turkish children were slightly older, smaller in size and weighed slightly more than their German peers (table 1). There was no significant difference between the two groups in the percentage of children who were either born 
Table 1. - Demographic characteristics of the study population

\begin{tabular}{lcc}
\hline & German $(\mathrm{n}=5030)$ & Turkish $(\mathrm{n}=451)$ \\
\hline Males \% & 48.6 & 49.7 \\
Age yrs & 9.8 & $10.0^{* * *}$ \\
Born in Munich $\%^{\dagger}$ & 77.8 & 78.2 \\
Height cm & 143.2 & $141.8^{* * *}$ \\
Weight kg & 34.6 & $36.3^{* * *}$ \\
\hline
\end{tabular}

***: $\mathrm{p}<0.001$ by Wilcoxon test. ${ }^{\dagger}$ : children who were born in Munich or moved to Munich in their first year of life.

in Munich or moved to Munich in their first year of life. Most of the children in the fourth-grade of primary school were between 9 and 11 yrs of age when they were tested. Of those children for whom the questionnaire was returned by their parents, 4,840 (4,451 German and 389 Turkish) underwent skin prick tests and 4,865 (4,505 German, 360 Turkish) underwent baseline lung function testing and cold air challenge.

There was a significant difference in the prevalence of asthma and asthma-related symptoms between Turkish and German children (table 2). The prevalence of asthma was lower in Turkish than in German children (5.3 versus 9.4\%). Furthermore, fewer Turkish parents reported symptoms of current asthma in their children. The frequency of wheezing and shortness of breath was significantly lower in Turkish than in German children, while Turkish parents reported cough with exercise, during foggy or cold weather more often in their children than did German parents.

There was no significant difference in the prevalence of hay fever between Turkish and German children. However, atopic dermatitis differed greatly between the two groups. Only $1.6 \%$ of Turkish parents reported atopic dermatitis in their children, whereas atopic dermatitis was reported to occur in $13.9 \%$ of German children.

Atopic sensitization, as assessed by skin prick tests, was significantly less frequent in Turkish children than in their German peers (table 2). Only $24.7 \%$ of Turkish school children presented a weal reaction of $\geq 3 \mathrm{~mm}$ to at least one

Table 2. - Prevalence (\%) of symptoms and diagnosis of respiratory and atopic diseases among children of German and Turkish nationality

\begin{tabular}{|c|c|c|}
\hline & $\begin{array}{l}\text { German } \\
(\mathrm{n}=5030)\end{array}$ & $\begin{array}{l}\text { Turkish } \\
(\mathrm{n}=451)\end{array}$ \\
\hline Asthma ever & 9.4 & $5.3^{*}$ \\
\hline Current asthma & 5.9 & 4.7 \\
\hline Wheezing & 17.0 & $8.6 * * *$ \\
\hline Shortness of breath & 8.7 & $4.2 *$ \\
\hline Cough with exercise & 11.7 & $18.4 * * *$ \\
\hline Hay fever & 8.6 & 10.0 \\
\hline Atopic dermatitis & 13.9 & $1.6^{* * *}$ \\
\hline Bronchitis & 15.9 & $6.4^{* * *}$ \\
\hline Atopic sensitization ${ }^{\dagger}$ & 36.7 & $24.7 * * *$ \\
\hline Dermatophagoides pteronyssinus & 10.3 & 9.3 \\
\hline Pollen (grass, birch, hazel) & 31.0 & $19.3 * * *$ \\
\hline Cat and dog dander & 24.7 & $1.9 * * *$ \\
\hline Bronchial hyperresponsiveness & 7.7 & $3.9 * * *$ \\
\hline
\end{tabular}

allergen tested, compared with $36.7 \%$ of the German pupils. When choosing different cut-off points $(2 \mathrm{~mm}$ and $4 \mathrm{~mm}$ ) for positivity of skin prick test reactions and when calculating the sum of all weal reactions as another measure of atopy, the difference between the two groups of children remained significant (data not shown). When analysing weal reactions to each allergen separately, significant differences were found for each allergen, although the difference in sensitization to house dust mites did not reach statistical significance (table 2 ).

No significant difference in baseline lung function was observed between Turkish and German school children when adjusting for sex, height and weight. The mean \pm SD FVC was $100.6 \pm 10.6 \%$ predicted in Turkish versus 100.4 $\pm 10.3 \%$ pred in German children, whereas the mean FEV1 was $100.6 \pm 10.9 \%$ pred in Turkish versus $100.1 \pm 10.1 \%$ pred in German children. The prevalence of BHR was lower in the Turkish group (table 2). Of the Turkish children only $3.9 \%$ reacted to the cold air hyperventilation challenge, whereas $7.7 \%$ of their German peers had a significant drop in FEV1 after the challenge.

To explore whether genetic or environmental differences between the study groups accounted for the observed variations in prevalence, potential risk factors for the development of atopic diseases were assessed (table 3 ). The family history of atopy, family size, passive smoke exposure, socioeconomic status, housing conditions, pet ownership and low birth weight were evaluated. A larger sibship size and higher passive smoke exposure were found in Turkish children, while a higher socioeconomic status (assessed by parental education), more pets at home and a higher prevalence of atopic dermatitis and hay fever in first-degree relatives were seen in German families (table 3). In contrast, there was no difference between Turkish and German children for a positive family history of asthma, housing conditions (heating and dampness at home) and birthweight (data not shown).

In multivariate analyses (tables 4 and 5) the relation of these potential risk factors to asthma (doctor's diagnosis of asthma ever), atopy and BHR was assessed. The crude odds ratio (OR) of Turkish nationality for asthma ever was 0.54 (confidence interval (CI) $0.34-0.87, \mathrm{p}<0.01$ ) and 0.57 (CI $0.44-0.72, p<0.001$ ) for atopic sensitization. A positive family history for atopy was significantly

Table 3. - Prevalence (\%) of potential risk factors for the development of atopic diseases

\begin{tabular}{|c|c|c|}
\hline & $\begin{array}{c}\text { German } \\
(\mathrm{n}=5030)\end{array}$ & $\begin{array}{l}\text { Turkish } \\
(\mathrm{n}=451)\end{array}$ \\
\hline Family history Asthma & 9.7 & 11.5 \\
\hline Hay fever & 26.6 & $10.4 *$ \\
\hline Atopic dermatitis & 18.4 & $5.3^{*}$ \\
\hline Number of siblings 0 & 25.6 & $7.8^{*}$ \\
\hline 1 & 50.8 & $36.5^{*}$ \\
\hline 2 & 17.0 & $31.9 *$ \\
\hline 3 & 6.5 & $23.9^{*}$ \\
\hline Passive smoking & 41.8 & $62.3^{*}$ \\
\hline Parental education $<8 \mathrm{yrs}$ & 0.4 & $9.2 *$ \\
\hline 8 yrs & 22.3 & $51.7 *$ \\
\hline $10 \mathrm{yrs}$ & 26.5 & 23.6 \\
\hline$>10$ yrs & 47.2 & $10.5^{*}$ \\
\hline Pets at home Cats or dogs & 24.7 & $1.9^{*}$ \\
\hline
\end{tabular}

*: $\mathrm{p}<0.05$ by Chi-squared test. 
Table 4. - Results of a multivariate logistic regression analysis with asthma ever and atopic sensitization as outcomes

\begin{tabular}{|c|c|c|c|c|c|c|}
\hline & \multicolumn{3}{|c|}{ Asthma ever } & \multicolumn{3}{|c|}{ Atopic sensitization } \\
\hline & OR & $95 \% \mathrm{CI}$ & p-value & OR & $95 \% \mathrm{CI}$ & p-value \\
\hline Turkish nationality & 0.53 & $(0.30-0.94)$ & 0.03 & 0.73 & $(0.55-0.96)$ & 0.03 \\
\hline Family history atopy & 1.64 & $(1.33-2.02)$ & 0.0001 & 1.64 & (1.44-1.87) & 0.0001 \\
\hline Education $^{\dagger}<8$ yrs & 0.24 & $(0.03-1.82)$ & 0.2 & 0.85 & $(0.43-1.70)$ & 0.7 \\
\hline 8 yrs & 0.82 & $(0.61-1.09)$ & 0.2 & 0.87 & $(0.73-1.04)$ & 0.1 \\
\hline $10 \mathrm{yrs}$ & 1.00 & - & - & 1.00 & - & - \\
\hline$>10 \mathrm{yrs}$ & 0.81 & $(0.64-1.03)$ & 0.09 & 0.94 & $(0.81-1.09)$ & 0.4 \\
\hline Number of siblings & 1.04 & $(0.94-1.16)$ & 0.5 & 0.91 & $(0.85-0.98)$ & 0.01 \\
\hline Passive smoking & 1.15 & $(0.93-1.43)$ & 0.2 & - & - & - \\
\hline Dog or cat & 1.01 & $(0.79-1.30)$ & 0.9 & 0.91 & $(0.78-1.06)$ & 0.2 \\
\hline
\end{tabular}

$\bar{\dagger}^{\dagger}$ : Highest level of father's or mother's education. OR: odds ratio; CI: confidence interval.

associated with a higher risk for asthma and atopy. Neither the number of siblings, passive smoking, pet ownership nor father's or mother's education showed a significant effect on the diagnosis of asthma and atopic sensitization. When Turkish nationality was added to the model, it still showed a significant negative association with asthma, atopic sensitization and BHR, suggesting that the risk factors included in the regression models did not explain the association between Turkish ethnicity and both asthma and atopic sensitization.

\section{Discussion}

The results of this study demonstrate that the prevalence of asthma and other atopic diseases differs between ethnic groups in Germany. Asthma and other atopic diseases were significantly less common in Turkish children living in Munich than in a comparable group of German children. When assessing risk factors for the development of asthma and other atopic diseases, significant differences between the two study groups were found (table 3). However, in multivariate regression models, none of these factors explained the lower prevalence of asthma, atopic sensitization and BHR in Turkish children.

Some methodological problems may exist with this study. It is possible that some Turkish children of this age group living in Munich were missed because of language or reading problems, even though the questionnaire was translated into Turkish. However, population counts in Munich, a city of 1.2 million inhabitants in the south of Germany, showed that of all children aged 9-11 yrs, 8.6\% are of Turkish nationality [16]. Therefore, an identification

Table 5. - Results of a multivariate linear regression analysis with per cent change in forced expiratory volume in one second (FEV 1 ) after cold air challenge as the dependent variable

\begin{tabular}{lcl}
\hline & $\beta$-Coefficient & $\mathrm{p}$-value \\
\hline Turkish nationality & -0.70 & 0.02 \\
Family history atopy & +0.15 & 0.35 \\
Sum of atopy & +0.58 & 0.001 \\
Passive smoking & -0.06 & 0.7 \\
Ratio FEV1/FVC & -10.97 & 0.0001 \\
\hline
\end{tabular}

FVC: forced vital capacity. ${ }^{\dagger}$ : additionally adjusted for height; ${ }^{*}$ : number of positive weal reactions. rate of $\sim 7 \%$ represents the proportion of Turkish children in this age group. Questions concerning the lifetime prevalence and doctor's diagnoses of atopic diseases are subject to recall bias and also reflect the attitude toward health issues and the accessibility of healthcare facilities, which may differ between German and Turkish families. In Turkish families, more fathers, who might not have the same insight into the children's health as the mother, filled out the questionnaire than in German families (31.1 versus $6.8 \%, \mathrm{p}<0.0001)$. When additionally controlling for the responding parent the effect of Turkish ethnicity on asthma decreased slightly $(\mathrm{OR}=0.59,95 \%$ CI $0.33-1.05, \mathrm{p}=0.07)$, but did not disappear. A similar prevalence of hay fever was found in Turkish and German children, although sensitization to pollen occurred less frequently in the Turkish subjects. This discrepancy might be attributable to translation problems, since the term hay fever is not a very commonly used expression in Turkish. This wording may thus have resulted in an overreporting of common cold symptoms rather than of symptoms of seasonal allergic rhinoconjunctivitis in the Turkish children. However, the differences in objective measures such as skin prick test results and BHR between Turkish and German children strongly suggest that the lower prevalence of asthma and atopy is real.

The present findings are consistent with the results reported from other studies stressing the important role of ethnicity for the development of asthma and atopic diseases in children $[8-11,13,17]$. The results of the present study demonstrate that ethnicity should be taken into consideration when performing epidemiological surveys in Europe as prevalence rates of atopic diseases may vary significantly between immigrant and indigenous populations. Similar results have previously been reported in studies of Asian immigrants to Australia [10], of Maoris [9] and South Pacific Islanders [11] who had immigrated to New Zealand, of Puerto Ricans [8] and Mexicans [17] living in the USA and of Asian children living in the UK [13]. Belonging to a certain ethnic group may lead to higher $[8,9]$ or lower $[10,11,13,17]$ prevalence rates of asthma and atopy compared with the indigenous population.

Genetic and environmental factors might account for the difference in the prevalence of asthma and other atopic diseases between ethnic groups. While atopic sensitization became increasingly frequent with the length of stay in a new environment $[10,12]$, such effects cannot explain the results of the present survey. Because most of the Turkish 
Table 6. - Comparison of asthma prevalence in Turkish children living in Germany and Turkey

\begin{tabular}{lccccccr}
\hline First author & {$[$ Ref.] } & Place & Location & Urban/rural & $\mathrm{n}$ & Ageyrs & Asthma prevalence $\%^{\dagger}$ \\
\hline This study & & Munich & Inland & Urban & 451 & $9-11$ & 5.3 \\
KALYONCU & {$[28]$} & Ankara & Inland & Urban & 1226 & $6-12$ & 17.4 \\
ONES & {$[30]$} & Istanbul & Coastal & Urban & 2340 & $6-12$ & 9.8 \\
KUCUKODUK & {$[29]$} & Bursa & Coastal & Rural & 3500 & $6-14$ & 10.2 \\
SELCUK & {$[31]$} & Edirne & Inland & Rural & 4522 & $7-12$ & 16.4 \\
\hline
\end{tabular}

${ }^{\dagger}$ : self-reported lifetime prevalence of physician-diagnosed asthma.

children enrolled in this study were either born in Munich or moved to Munich in their first year of life (78.2\%), it can be assumed that the majority of these children represent the second generation of Turkish immigrants living in Germany. This suggests that Turkish and German children grew up in similar outdoor environments.

Moreover, indoor factors and lifestyle may differ. Therefore, potential risk factors were evaluated, which had shown an association with childhood asthma and other atopic diseases in previous studies: a positive family history of atopy [18], fewer siblings [19], exposure to environmental tobacco smoke [20], low socioeconomic status [20], poor housing conditions [21], pet ownership [22] and low birthweight [23]. Apart from a positive family history of atopy, which significantly increased the risk of asthma and atopic sensitization, only Turkish origin was significantly negatively associated with asthma, atopy and BHR. These findings indicate that either environmental factors closely related to Turkish ethnicity that were not assessed, or genetic factors account for the effect of Turkish origin in these data. Since Turkish and German children grow up in different social and cultural settings, different dietary habits [24] or differences in exposure to car traffic [25] or indoor pollutants may be factors that were not evaluated but which may have contributed to the development of different diseases. The higher prevalence of cough with exercise, foggy or cold weather in Turkish children (table 2) might, for example, be attributable to the higher exposure to environmental tobacco smoke of the Turkish children. Since cough without wheezing has been shown to be independent of childhood asthma and atopic diseases [26], the higher prevalence of cough in the present data reflecting bronchitic rather than asthmatic symptoms is consistent with an overall lower prevalence of asthma, BHR and atopy in the Turkish population.

Variations in the genetic background of different ethnic groups [27] may also explain the differences in the prevalence of childhood asthma and atopic diseases. If genetic differences were responsible for the reduced prevalence of asthma in Turkish children in Germany, one might expect that studies in Turkish children living in Turkey [28-31] would find the same low prevalence of asthma. Surprisingly, this is not the case (table 6). In Turkey, self-reported prevalence rates for physician-diagnosed asthma using comparable definitions varied between 7.9 [29] and $17.4 \%$ [28] and were similar to those found in German children living in Munich.

Therefore, it is proposed that the lower prevalence of asthma and allergic diseases in this Turkish study group is in part owing to a selection bias associated with immigration. Healthy individuals may have chosen to leave their country of origin and work abroad. In Germany, most positions offered to immigrants are of low quality and are physically demanding. This effect of preselecting healthy individuals for physically demanding jobs is well known in occupational medicine, where it is referred to as a "preemployment healthy worker effect" [32]. As a consequence of migration selection, the offspring of Turkish immigrants may have a lower risk of asthma and atopic diseases. In fact, the prevalence of hay fever and atopic dermatitis was significantly lower in Turkish than in German families, although asthma occurred with a similar frequency. The assessment of a history of asthma in the parents is prone to misclassification since only a crude question asking for the presence of asthma in first-degree relatives was used. Since Turkish fathers smoked more frequently than German fathers (56.0 versus $30.0 \%, \mathrm{p}<$ 0.001 ) a misclassification of chronic obstructive pulmonary disease as asthma may have occurred more frequently in the Turkish fathers, thus preferentially overestimating the familial predisposition for asthma in Turkish families. Owing to this possible bias, the true overall genetic predisposition for atopic diseases might be lower in Turkish families living in Munich than in German families.

In conclusion, the results of this study show that Turkish children living in Germany have a lower prevalence of asthma and atopic diseases than their German peers. These differences may be attributable to a genetic selection effect of healthy families migrating to Germany or unknown environmental factors related to the lifestyle of these Turkish families living in Germany. The importance of evaluating ethnic differences when studying childhood atopic diseases in Europe should be emphasized.

\section{References}

1. International Study of Asthma and Allergies in Childhood (ISAAC) Steering Committee. Worldwide variation in prevalence and symptoms of asthma, allergic rhinoconjunctivitis, and atopic eczema: ISAAC. Lancet 1998; 351: $1225-1232$

2. Pearce N, Weiland S, Keil U, et al. Self-reported prevalence of asthma symptoms in children in Australia, England, Germany and New Zealand: an international comparison using the ISAAC protocol. Eur Respir $J$ 1993; 6: 1455-1461.

3. von Mutius E, Martinez FD, Fritzsch C, Nicolai T, Roell $\mathrm{G}$, Thiemann HH. Prevalence of asthma and atopy in two areas of West and East Germany. Am J Respir Crit Care Med 1994; 149: 358-364.

4. Vasar M, Braback L, Julge K, Knutsson A, Riikjarv MA, Bjorksten B. Prevalence of bronchial hyperreactivity as determined by several methods among Estonian schoolchildren. Pediatr Allergy Immunol 1996; 7: 141-146.

5. Braback L, Breborowicz A, Dreborg S, Knutsson A, Pieklik H, Bjorksten B. Atopic sensitization and respiratory symptoms among Polish and Swedish school children. Clin Exp Allergy 1994; 24: 826-835. 
6. Esamai F, Anabwani GM. Prevalence of asthma, allergic rhinitis and dermatitis in primary school children in Uasin Gishu district, Kenya. East Afr Med J 1996; 73: 474-478.

7. Pekkanen J, Remes ST, Husman T, et al. Prevalence of asthma symptoms in video and written questionnaires among children in four regions of Finland. Eur Respir $J$ 1997; 10: 1787-1794.

8. Beckett WS, Belanger K, Gent JF, Holford TR, Leaderer BP. Asthma among Puerto Rican Hispanics: a multiethnic comparison study of risk factors. Am J Respir Crit Care Med 1996; 154: 894-899.

9. Pattemore PK, Asher MI, Harrison AC, Mitchell EA, Rea $\mathrm{HH}$, Stewart AW. Ethnic differences in prevalence of asthma symptoms and bronchial hyperresponsiveness in New Zealand schoolchildren. Thorax 1989; 44: 168-176.

10. Leung RC, Carlin JB, Burdon JG, Czarny D. Asthma, allergy and atopy in Asian immigrants in Melbourne. Med J Aust 1994; 161: 418-425.

11. Crane J, O'Donnell TV, Prior IA, Waite DA. Symptoms of asthma, methacholine airway responsiveness and atopy in migrant Tokelauan children. N Z Med J 1989; 102: 36-38.

12. Kalyoncu AF, Stalenheim G. Serum IgE levels and allergic spectra in immigrants to Sweden. Allergy 1992; 47: 277-280.

13. Pararajasingam CD, Sittampalam L, Damani P, Pattemore PK, Holgate ST. Comparison of the prevalence of asthma among Asian and European children in Southampton. Thorax 1992; 47: 529-532.

14. Berbig B, von Mutius E, Nicolai T, Stiepel E, Adam D. Comparing the multitest to a conventional skin prick test. Allergologie 1991; 14: 51-57.

15. Nicolai T, von Mutius E, Reitmeir P, Wjst M. Reactivity to cold-air hyperventilation in normal and in asthmatic children in a survey of 5,697 schoolchildren in southern Bavaria. Am Rev Respir Dis 1993; 147: 565-572.

16. Statistisches Bundesamt Deutschland. Bevölkerungsdaten 1996. Bonn, 1998.

17. Dodge R. A comparison of the respiratory health of Mexican-American and non-Mexican-American white children. Chest 1983; 84: 587-592.

18. von Mutius E, Nicolai T. Familial aggregation of asthma in a South Bavarian population. Am J Respir Crit Care Med 1996; 153: 1266-1272.
19. Strachan DP. Hay fever, hygiene, and household size. BMJ 1989; 299: 1259-1260.

20. Morgan WJ, Martinez FD. Risk factors for developing wheezing and asthma in childhood. Pediatr Clin North Am 1992; 39: 1185-1203.

21. Strachan DP. Damp housing and childhood asthma: validation of reporting of symptoms. BMJ 1988; 297: 12231226.

22. Brunekreef B, Groot B, Hock G. Pets, allergy and respiratory symptoms in children. Int J Epidemiol 1992; 21: 338-342.

23. von Mutius E, Nicolai T, Martinez FD. Prematurity as a risk factor for asthma in preadolescent children. $J$ Pediatr 1993; 123: 223-229.

24. Carey OJ, Cookson JB, Britton J, Tattersfield AE. The effect of lifestyle on wheeze, atopy, and bronchial hyperreactivity in Asian and white children. Am J Respir Crit Care Med 1996; 154: 537-540.

25. Nicolai T, von Mutius E. Respiratory hypersensitivity and environmental factors: East and West Germany. Toxicol Lett 1996; 86: 105-113.

26. Wright AL, Holberg CJ, Morgan WJ, Taussig LM, Halonen M, Martinez FD. Recurrent cough in childhood and its relation to asthma. Am J Respir Crit Care Med 1996; 153: 1259-1265.

27. Daniels SE, Bhattacharrya S, James A, et al. A genomewide search for quantitative trait loci underlying asthma. Nature 1996; 383: 247-250.

28. Kalyoncu AF, Selcuk ZT, Karakoca Y, et al. Prevalence of childhood asthma and allergic diseases in Ankara, Turkey. Allergy 1994; 49: 485-488.

29. Kucukoduk S, Aydin M, Cetinkaya F, Dinc H, Gurses N, Saraclar Y. The prevalence of asthma and other allergic diseases in a province of Turkey. Turk J Pediatr 1996; 38: 149-153.

30. Ones U, Sapan N, Somer A, et al. Prevalence of childhood asthma in Istanbul, Turkey. Allergy 1997; 52: 570575 .

31. Selcuk ZT, Caglar T, Enunlu T, Topal T. The prevalence of allergic diseases in primary school children in Edime, Turkey. Clin Exp Allergy 1997; 27: 262-269.

32. Wen CP, Tsai SP, Gibson RL. Anatomy of the healthy worker effect: a critical review. J Occup Med 1983; 25: 283-289. 